\title{
Consumo e dinâmica ruminal da fibra em detergente neutro em bovinos em pastejo no período das águas recebendo suplementação com nitrogênio não-proteico elou proteína verdadeira ${ }^{1}$
}

\author{
Viviane Aparecida Carli Costa ${ }^{2}$, Edenio Detmann ${ }^{3}$, Mário Fonseca Paulino ${ }^{3}$, Sebastião de \\ Campos Valadares Filho ${ }^{3}$, Lara Toledo Henriques ${ }^{4}$, Isabela Pena Carvalho de Carvalho ${ }^{5}$, \\ Tiago Neves Pereira Valente ${ }^{2}$
}

\footnotetext{
1 Trabalho conduzido com apoio do CNPq, FAPEMIG (PPM) e INCT-Ciência Animal.

2 Laboratório de Zootecnia e Nutrição Animal, Universidade Estadual do Norte Fluminense, Campos dos Goytacazes-RJ.

${ }^{3}$ Departamento de Zootecnia, Universidade Federal de Viçosa, Viçosa-MG. Pesquisador do CNPq e do INCT-Ciência Animal

${ }^{4}$ Centro de Ciências Agrárias, Universidade Federal da Paraíba, Areia-PB.

${ }^{5}$ Departamento de Zootecnia, Universidade Estadual Paulista, Jaboticabal-SP.
}

RESUMO - Objetivou-se avaliar o efeito de diferentes relações entre proteína verdadeira e nitrogênio não-proteico sobre o consumo e a dinâmica de trânsito e degradação ruminal da fibra em detergente neutro (FDN) da forragem em bovinos em pastejo durante o período das águas. Foram utilizados cinco novilhos mestiços Holandês $\times$ Zebu, castrados, com peso corporal inicial de $335 \pm 35 \mathrm{~kg}$ fistulados no rúmen e no abomaso. Os tratamentos foram: controle (somente pasto); e suplementos com ureia; com 2/3 de compostos nitrogenados oriundos da ureia e 1/3 de compostos nitrogenados oriundos da albumina; com 1/3 de compostos nitrogenados oriundos da ureia e 2/3 de compostos nitrogenados oriundos da albumina; e com albumina. Foram fornecidos $200 \mathrm{~g} /$ dia de proteína bruta (PB) a partir dos suplementos. O experimento foi conduzido segundo delineamento em quadrado latino $5 \times 5$, com cinco períodos experimentais de 15 dias. Não foram observados efeitos da suplementação sobre o consumo voluntário, com exceção do consumo de PB, que aumentou com a suplementação. A substituição da ureia por albumina nos suplementos teve efeito linear sobre o consumo de PB. Os consumos dos demais componentes da dieta não foram afetados pela composição dos suplementos. Nenhum efeito foi observado sobre a taxa de passagem ruminal de compostos fibrosos. O fornecimento de suplementos ampliou, em média, a estimativa da taxa comum de latência e degradação da FDN. Contudo, não houve efeito da alteração na composição dos suplementos sobre este parâmetro. A suplementação de bovinos com fontes de compostos nitrogenados degradáveis no rúmen proteicos ou não-proteicos durante o período das águas não afeta o consumo voluntário de pasto.

Palavras-chave: albumina, consumo de pasto, suplementação, ureia

\section{Intake and rumen dynamics of neutral detergent fiber in grazing cattle supplemented with non-protein nitrogen and, or true protein during the rainy season}

\begin{abstract}
The objective of this study was to evaluate the effect of different true protein:non-protein nitrogen ratios in supplements on intake and ruminal transit and degradation dynamics of neutral detergent fiber (NDF) in grazing cattle during rainy season. Five crossbred Holstein $\times$ Zebu steers, averaging $335 \pm 35 \mathrm{~kg}$ of body weight and fitted with rumen and abomasum canullaes were used. The treatments were: control (only pasture), and supplements based on urea, 2/3 of nitrogenous compounds from urea and 1/3 of nitrogenous compounds from albumin, $1 / 3$ of nitrogenous compounds from urea and 2/3 of nitrogenous compounds from albumin, and albumin. Two hundred grams/d of crude protein (CP) were supplied from supplements. The experiment was carried out according to a $5 \times 5$ Latin square design, with five 15 -day experimental periods. There were no effects of supplementation on voluntary intake, except for CP intake, which was increased by supplementation. The replacement of urea by albumin in the supplements caused linear effect on the CP intake. The intakes of the other diet components were not affected by the supplement composition. There was no effect on ruminal rate of passage of fibrous compounds. Supplementation increased the estimates of common rate of lag and degradation of NDF. However, no effect of supplement composition alteration was observed on this parameter. Supplementation of cattle with rumen degradable (protein or non-protein) nitrogenous compounds for grazing cattle during rainy season does not affect voluntary intake of pasture.
\end{abstract}

Key Words: albumin, pasture intake, supplementation, urea 


\section{Introdução}

Resultados de pesquisas conduzidas em condições tropicais têm evidenciado que a suplementação proteica, incluindo, em alguns casos, o uso de ureia como principal composto nitrogenado dos suplementos, melhora o desempenho animal durante o período das águas (Porto et al., 2009; Figueiredo et al., 2008; Paulino et al., 2008).

Contudo, em trabalhos conduzidos em ambiente in vitro utilizando forragens tropicais de alta qualidade, similares às observadas em pastagens durante o período das águas, Paez-Bernal (2007), Costa et al. (2009) e Zorzi et al. (2009) verificaram que a suplementação exclusiva com proteína verdadeira pode causar efeitos deletérios sobre a utilização microbiana da fibra em detergente neutro (FDN), ao passo que a suplementação com ureia permitiria ampliação do crescimento microbiano sobre a FDN (Paez-Bernal, 2007; Zorzi et al., 2009). Entretanto, ponto de equilíbrio entre compostos nitrogenados proteicos e não-proteicos parece definir a máxima utilização dos substratos fibrosos basais (Paez-Bernal, 2007; Zorzi et al., 2009).

Esses efeitos deletérios da suplementação exclusiva com proteína verdadeira sobre a utilização de carboidratos fibrosos, denominados “efeito proteína” (Costa et al., 2009) são comumente observados na literatura (Cone \& Van Gelder, 1999; Oliveira et al., 2005) e parecem estar associados ao estímulo sobre o crescimento de espécies não-fibrolíticas, ampliando a competição por substratos essenciais no ambiente ruminal (Carvalho et al., 2011).

Por outro lado, as exigências de microrganismos fibrolíticos, em termos de concentração ótima de nitrogênio amoniacal ruminal, parecem ser superiores às de microrganismos não-fibrolíticos (McCallan \& Smith, 1983; Detmann et al., 2009). Estudos in vitro evidenciam que, sob condições similares de equivalentes proteicos suplementares, a ureia é mais eficiente em implementar níveis de nitrogênio amoniacal no rúmen (Zorzi et al., 2009), o que poderia influenciar diretamente o crescimento microbiano sobre a FDN.

Contudo, informações sobre a influência de suplementação com base em compostos nitrogenados sobre a utilização de forragens tropicais de alta qualidade sob pastejo in vivo são escassas na literatura nacional.

Assim, objetivou-se avaliar os efeitos de diferentes relações entre proteína verdadeira e nitrogênio nãoproteico em suplementos para bovinos em pastejo de capim-braquiária (Brachiaria decumbens Stapf.) durante o período das águas sobre o consumo e as dinâmicas de trânsito e degradação ruminal da fibra em detergente neutro da forragem.

\section{Material e Métodos}

O experimento foi conduzido no Setor de Bovinocultura de Corte do Departamento de Zootecnia da Universidade Federal de Viçosa, Minas Gerais, entre dezembro de 2007 e março de 2008 (período das águas).

Foram utilizados cinco novilhos mestiços Holandês $\times$ Zebu, castrados, com peso corporal (PC) inicial de $335 \pm 35 \mathrm{~kg}$ fistulados no rúmen e no abomaso. A área experimental foi composta de cinco piquetes de capim-braquiária, com 0,34 ha cada, contendo bebedouro e comedouro coberto, sendo cada animal manejado em um piquete. Paralelamente aos piquetes, situava-se o curral de manejo, no qual foram realizadas as coletas nos animais (fezes, conteúdo ruminal, etc). Todos os animais tiveram acesso irrestrito a água e mistura mineral completa (9\% de fósforo).

Foram avaliados os seguintes tratamentos: controle (MM) (somente mistura mineral); suplementação com ureia (U); suplementação com 2/3 de compostos nitrogenados oriundos da ureia e $1 / 3$ de compostos nitrogenados oriundos da albumina ( $2 / 3 \mathrm{U})$; suplementação com $1 / 3$ de compostos nitrogenados oriundos da ureia e 2/3 de compostos nitrogenados oriundos da albumina (1/3U); e suplementação com albumina (A).

Os suplementos foram fornecidos de forma a suprir 200 g de proteína bruta (PB) a cada animal, diariamente às 12 h, por intermédio da fistula ruminal. Este nível de suplementação visou suprir aproximadamente 30\% das exigências de proteína degradável no rúmen, tomando-se como base um novilho zebuíno, castrado, com 350 kg de PC e ganho esperado de $1 \mathrm{~kg} /$ dia (Valadares Filho et al., 2006).

As fontes alimentares utilizadas na formulação dos suplementos foram escolhidas de forma a contrastarem-se fontes e proporções de compostos nitrogenados de origem proteica (albumina) e não-proteica (ureia:sulfato de amônio, 9:1).

O experimento foi conduzido segundo delineamento em quadrado latino $5 \times 5$, com cinco períodos experimentais de 15 dias, cada, de modo que os cinco primeiros dias foram destinados à adaptação dos animais à suplementação.

No primeiro dia de cada período experimental, quantificou-se a massa de forragem disponível em cada piquete por intermédio do corte rente ao solo de cinco áreas delimitadas por um quadrado de dimensões $0,5 \times 0,5 \mathrm{~m}$, selecionadas ao acaso em cada piquete. As amostras, depois de pesadas, foram avaliadas quanto ao teor de matéria seca (MS) (Silva \& Queiroz, 2002). A disponibilidade média de forragem foi de 11,$3 ; 14,1 ; 12,9 ; 14,2$ e 13,4 t MS/ha para os períodos experimentais sequencialmente. 
A avaliação do pasto ingerido pelos animais foi realizada no primeiro, quinto e décimo dias de cada período experimental por simulação manual de pastejo. As amostras foram secas sob ventilação forçada $\left(60^{\circ} \mathrm{C}\right)$, processadas em moinho de facas ( 1 e $2 \mathrm{~mm}$ ) e posteriormente compostas, como base no peso seco ao ar, por piquete e período experimental.

Para estimação da excreção fecal, utilizou-se dióxido de titânio como indicador externo, fornecido na quantidade de $20 \mathrm{~g} /$ dia a cada animal, às $12 \mathrm{~h}$, via fístula ruminal, entre o primeiro e oitavo dias de cada período experimental. As coletas fecais foram realizadas de acordo com o cronograma: $6^{0}$ dia, às 8 h e 14 h; 70 dia, às 10 h e 16 h; e $8^{\circ}$ dia, às 12 h e $18 \mathrm{~h}$. As amostras de fezes foram secas sob ventilação forçada $\left(60^{\circ} \mathrm{C}\right.$ ) e processadas em moinho de facas (1 e $2 \mathrm{~mm}$ ). Posteriormente, elaboraram-se amostras compostas, com base no peso seco ao ar, por animal e período experimental.

Do $10^{0}$ ao $15^{\text {o }}$ dia do período experimental, foi realizado procedimento para avaliação da cinética de trânsito gastrintestinal de partículas fibrosas, baseado no fornecimento de indicador externo, em procedimento de dose-pulso (Ellis et al., 1994), com uso de cromo mordente à fibra como indicador, produzido conforme descrição de Udén et al. (1980). A base fibrosa para produção do indicador foi retirada de amostras de pasto, obtidas por simulação manual de pastejo no primeiro dia de cada período experimental. Para simulação da atividade inicial de mastigação pelo animal, as amostras foram submetidas a um processo de moagem tripla em moinho de facas, sem peneira, segundo Detmann et al. (2005a).

Foram fornecidos para cada animal $100 \mathrm{~g}$ de fibra mordente, diretamente no rúmen, às $8 \mathrm{~h}$ do $10^{\circ}$ dia, obtendo-se as amostras fecais diretamente do reto dos animais às 0,3 , $6,9,12,18,24,30,36,48,60,72,84,96,108$ e 120 horas após o fornecimento do indicador. As amostras foram secas sob ventilação forçada $\left(60^{\circ} \mathrm{C}\right)$ e processadas em moinho de facas (1 mm).

Simultaneamente a esta avaliação, foi conduzido procedimento de incubação in situ para quantificação dos eventos da dinâmica de degradação ruminal da FDN. Amostras de pasto obtidas via simulação manual de pastejo (primeiro dia de cada período experimental), depois de secas sob ventilaç ão forçada $\left(60^{\circ} \mathrm{C}\right)$ e processadas em moinho de facas ( $2 \mathrm{~mm}$ ), foram acondicionadas em sacos de tecido-não-tecido (TNT, $100 \mathrm{~g} / \mathrm{m}^{2}$ ) (Casali et al., 2008), com dimensões $4 \times 5 \mathrm{~cm}$, na proporção de $25 \mathrm{mg} \mathrm{MS} / \mathrm{cm}^{2}$ de superfície. As amostras foram incubadas em duplicata para cada tempo de incubação no rúmen dos animais. Empregaram-se os seguintes tempos de incubação: 0, 3, 6, $9,12,24,36,48,60,72,96$ e 120 horas. Os sacos foram dispostos em ordem inversa no tocante aos tempos de incubação, de forma a serem retirados simultaneamente, sendo então lavados em água corrente e secos sob ventilação forçada $\left(60^{\circ} \mathrm{C}\right)$.

As amostras de pasto obtidas via simulação manual e fezes processadas em moinho de facas com peneira de porosidade $1 \mathrm{~mm}$ foram avaliadas quanto aos teores de MS, matéria orgânica (MO), proteína bruta, extrato etéreo (EE), fibra em detergente ácido (FDA) e lignina $\left(\mathrm{H}_{2} \mathrm{SO}_{4} 72 \% \mathrm{p} / \mathrm{p}\right)$, segundo técnicas descritas por Silva \& Queiroz (2002). Os teores de fibra em detergente neutro (FDN) foram estimados segundo recomendações de Mertens (2002). As correções quanto aos teores de cinzas e proteína na FDN e na FDA foram conduzidas conforme recomendações de Mertens (2002) e Licitra et al. (1996), respectivamente. Os suplementos foram avaliados quanto à composição de MS, MO, PB e EE, conforme as técnicas supracitadas (Tabela 1).

Os teores de CNF foram obtidos segundo Detmann \& Valadares Filho (2010):

$C N F=M O-[E E+F D N c p+(P B-P B u+U)]$

em que: $\mathrm{CNF}=$ teor de carboidratos não-fibrosos (\%); $\mathrm{MO}=$ teor de matéria orgânica (\%); EE = teor de extrato etéreo (\%); FDNcp = teor de fibra em detergente neutro corrigida para cinzas e proteína (\%); PB = teor de proteína bruta (\%); $\mathrm{PBu}=$ teor de proteína bruta oriunda da ureia (\%); $\mathrm{U}=$ teor de ureia (\%).

As amostras fecais referentes à avaliação de consumo foram avaliadas por colorimetria quanto ao teor de dióxido de titânio, segundo método descrito por Titgmeyer et al. (2001). A excreção fecal foi estimada como a relação entre dose e concentração fecal do indicador.

As estimativas de consumo voluntário foram obtidas utilizando-se a FDN indigestível (FDNi) como indicador interno, quantificada por procedimento de incubação in situ por 240 horas em amostras processadas a $2 \mathrm{~mm}$, segundo recomendações de Casali et al. (2008).

O consumo foi estimado adaptando-se as recomendações de Detmann et al. (2001a), uma vez que os suplementos eram isentos de FDNi:

$C M S=C M S F o r+C M S S U P=\frac{(E F \times C I F z)}{C I F o r}+C M S S u p$

em que: $\mathrm{CMS}$ = consumo de MS (g/dia); EF = excreção fecal (g/dia); $\mathrm{CIFz}=$ concentração de FDNi nas fezes (g/g); CMSFor = consumo de MS de forragem $(\mathrm{g} / \mathrm{dia})$; CMSSup = consumo de MS de suplemento (g/dia); e CIFor = concentração de FDNi na forragem (g/g).

As amostras de pasto relativas à disponibilidade total de forragem foram analisadas quanto aos teores de FDN (Mertens, 2002) e FDNi (Casali et al., 2008) objetivando-se 
Tabela 1 - Composição química do pasto e dos suplementos

\begin{tabular}{|c|c|c|c|c|c|}
\hline \multirow[t]{2}{*}{ Item } & \multicolumn{4}{|c|}{ Suplemento } & \multirow[b]{2}{*}{ Pasto $^{2}$} \\
\hline & Ureia & $2 / 3$ ureia $+2 / 3$ albumina & $1 / 3$ ureia $+2 / 3$ albumina & Albumina & \\
\hline Matéria seca, \% da matéria natura & 98,20 & 97,24 & 96,26 & 95,30 & $22,05 \pm 0,87$ \\
\hline Matéria orgânica, \% da MS & 99,76 & 99,18 & 98,58 & 98,00 & $91,20 \pm 0,25$ \\
\hline Proteína bruta, \% da MS & 256,11 & 197,83 & 137,79 & 79,52 & $9,99 \pm 0,32$ \\
\hline Extrato etéreo, \% da MS & 0,0 & 0,81 & 1,64 & 2,45 & $1,54 \pm 0,06$ \\
\hline Fibra em detergente neutro, \% da MS & - & - & - & - & $71,42 \pm 0,61$ \\
\hline FDNcp, \% da MS & - & - & - & - & $63,93 \pm 0,76$ \\
\hline PIDN, \% da PB & - & - & - & - & $25,16 \pm 0,85$ \\
\hline Carboidratos não-fibrosos, \% da MS $^{1}$ & 0,0 & 5,13 & 10,66 & 16,03 & $15,75 \pm 0,47$ \\
\hline Fibra em detergente ácido, \% da MS & - & - & - & - & $41,69 \pm 0,51$ \\
\hline FDAcp, \% da MS & - & - & - & - & $30,31 \pm 0,83$ \\
\hline PIDA, \% da PB & - & - & - & - & $7,90 \pm 0,33$ \\
\hline Lignina, \% da MS & - & - & - & - & $4,05 \pm 0,12$ \\
\hline FDNi, \% da MS & - & - & - & - & $17,81 \pm 0,45$ \\
\hline
\end{tabular}

${ }^{1} \mathrm{CNF}=\mathrm{MO}-[\mathrm{EE}+\mathrm{FDNCP}+(\mathrm{PB}-\mathrm{PBu}+\mathrm{U})]$.

${ }^{2}$ Média \pm erro-padrão da média (amostras obtidas por simulação manual de pastejo).

FDNcp = fibra em detergente neutro corrigida para cinzas e proteína; PIDN = proteína insolúvel em detergente neutro; FDAcp = fibra em detergente ácido corrigida para cinzas e proteína; PIDA = proteína insolúvel em detergente ácido; $\mathrm{FDNi}$ = fibra em detergente neutro indigestível.

a avaliação do percentual de MS potencialmente digestível (MSpd) da forragem, segundo Paulino et al. (2008):

$M S p d=0,98 \times(100-F D N)+(F D N-F D N i)$

em que: MSpd = teor de MS potencialmente digestível na forragem (\% da MS); e FDN e FDNi = teores de FDN e FDNi na forragem, respectivamente (\% da MS).

As amostras de fezes relativas aos procedimentos para quantificação dos parâmetros da cinética de trânsito foram analisadas quanto aos teores de MS (Silva \& Queiroz, 2002) e cromo (Willians et al., 1962).

Os parâmetros da cinética de trânsito foram estimados por ajustamento à curva de excreção fecal do indicador do modelo gama-2 tempo-dependente descrito por Ellis et al. (1994):

$C_{t}=Z \times(t-\tau) \times \gamma \times \exp [-\gamma \times(t-\tau)]$

em que: $\mathrm{C}_{\mathrm{t}}=$ concentração fecal do indicador no tempo " $\mathrm{t}$ " (ppm); $\mathrm{t}$ = tempo após o fornecimento do indicador (h); $\gamma=$ parâmetro taxa tempo-dependente relativo ao fluxo ruminal de partículas fibrosas $\left(\mathrm{h}^{-1}\right)$; $\mathrm{Z}$ = parâmetro sem interpretação biológica direta (ppm $\times \mathrm{h}$ ); e $\tau=$ tempo decorrido entre a aplicação e o aparecimento do indicador nas fezes ou tempo de trânsito intestinal (h).

Os tempos médios de retenção no rúmen-retículo e no trato gastrintestinal total foram estimados pelas equações seguintes, segundo Ellis et al. (1994):

$T M R R=\frac{2}{\gamma}$

$T M R T=T M R R+\tau$

em que: TMRR = tempo médio de retenção no rúmenretículo (h); TMRT = tempo médio de retenção total (h); e $\gamma$ e $\tau=$ como definidos anteriormente.
Os resíduos de degradação ruminal foram analisados quanto ao teor de FDN em aparelho analisador de fibras $\left(\right.$ Ankom ${ }^{220}$ ). Os perfis de degradação da FDN foram interpretados por intermédio do modelo logístico descrito por Van Milgen et al. (1991):

$R_{t}=B \times(1+\lambda \times t) \times \exp (-\lambda \times t)+I$

em que: $\mathrm{R}_{\mathrm{t}}=$ resíduo não-degradado de FDN no tempo $\mathrm{t}(\%)$; $\mathrm{B}$ = fração potencialmente degradável (\%); I = fração indegradável (\%); e $\lambda$ = taxa fracional conjunta de latência e degradação $\left(\mathrm{h}^{-1}\right)$.

As estimativas de latência discreta foram obtidas segundo derivações de Vieira et al. (1997):

$L A G=\frac{R(0)-R\left(t_{i}\right)}{R^{\prime}\left(t_{i}\right)}+t_{i}$

em que: $\mathrm{LAG}=$ latência discreta $(\mathrm{h}) ; \mathrm{R}(0)$ = resíduo de FDN não-degradado em $\mathrm{t}=0(\%) ; \mathrm{R}\left(\mathrm{t}_{\mathrm{j}}\right)=$ resíduo nãodegradado de FDN obtido no ponto de inflexão da curva de degradação (\%); $\mathrm{R}^{\prime}\left(\mathrm{t}_{\mathrm{i}}\right)$ = derivada da curva ajustada de degradação para o ponto de inflexão (máxima taxa de degradação do substrato) $\left(\mathrm{h}^{-1}\right)$; e $\mathrm{t}_{\mathrm{i}}=$ tempo equivalente ao ponto de inflexão da curva de degradação (h).

Os valores de $t_{\mathrm{i}}$ foram obtidos segundo Van Milgen et al. (1991):

$t_{i}=\frac{1}{\lambda}$

As frações B e I foram expressas na forma padronizada, segundo sugestões de Waldo et al. (1972).

$B p=\frac{B}{B+I}$

$I p=\frac{B}{B+I}$ 
A fração efetivamente degradada da FDN foi obtida em adaptação às sugestões de Ørskov \& McDonald (1979), segundo a equação:

$$
F E D=\lim _{t \rightarrow \infty} \int_{0}^{t}\left[f(t) \times\left(-\frac{d R t}{d t}\right)\right] d t
$$

em que: FED = fração efetivamente degradada da FDN (\%); $f(t)$ = função relativa ao deslocamento de sólidos no ambiente ruminal.

A função $f(t)$ foi obtida por reparametrização de (4), reinterpretando-se o perfil excretório obtido de partículas emergentes para partículas residentes (Ellis et al., 1994):

$f(t)=(1+\gamma \times t) \times \exp (-\gamma \times t)$

As estimativas do efeito de repleção ruminal da FDN foram obtidas por adaptações às proposições de Waldo et al. (1972), segundo as equações:

$R R p d=\lim _{t \rightarrow \infty} \int_{0}^{t}[B p \times(1+\lambda \times t) \times \exp (-\lambda \times t) \times(1+\gamma \times t) \times \exp (-\gamma \times t)] d t(14) ;$

$R R i=\lim _{t \rightarrow \infty} \int_{0}^{t}[\operatorname{Ip} \times(1+\gamma \times t) \times \exp (-\gamma \times t)] d t$

$R R t=R R p d+R R i$

em que: RRt = efeito de repleção ruminal total da FDN (h); RRpd = efeito de repleção ruminal atribuído à fração potencialmente degradável da FDN (h); e RRi = efeito de repleção ruminal atribuído à fração indegradável da FDN (h).

O experimento foi analisado segundo delineamento em quadrado latino $5 \times 5$ com cinco tratamentos, cinco animais e cinco períodos experimentais.

Para avaliação do consumo voluntário, a soma de quadrados de tratamentos foi decomposta por intermédio de contrastes ortogonais (Tabela 2) utilizando-se o programa SAS (Statistical Analysis System, versão 9.1), adotando-se 0,10 como nível crítico de probabilidade para o erro tipo I.

Para os ajustamentos não-lineares relativos às equações (4) e (7), utilizou-se o algoritmo iterativo de Gauss-Newton implementado no PROC NLIN do SAS. A comparação entre tratamentos foi realizada por meio da distribuição de $\chi^{2}$ segundo o teste de identidade de modelos não-lineares proposto por Regazzi (2003). Neste caso, três hipóteses foram avaliadas: diferença global entre tratamentos; diferença entre o tratamento controle e os tratamentos que envolveram suplementação; e diferença entre tratamentos que envolveram suplementação. Adotou-se 0,10 como nível crítico de probabilidade assintótica para o erro tipo I.

Para a cinética de trânsito, esses testes foram aplicados somente aos parâmetros $\gamma$ e $\tau$, uma vez que o parâmetro $Z$ não apresenta sentido biológico (Equação 4). Para a cinética de degradação, avaliou-se somente o parâmetro $\lambda$ (Equação 7) sob o pressuposto de as frações potencialmente degradável e indegradável constituírem características inerentes ao substrato (Detmann et al., 2008). As estimativas dos demais parâmetros, por serem derivados dos parâmetros acima listados, foram avaliadas descritivamente.

\section{Resultados}

Não foram observados efeitos da suplementação sobre o consumo voluntário ( $\mathrm{P}>0,10)$, com exceção do consumo de $\mathrm{PB}$, que aumentou com a suplementação $(\mathrm{P}<0,10)$ (Tabela 3).

A ausência de efeitos da suplementação $(\mathrm{P}>0,10)$ sobre o consumo de MS de pasto e de FDNcp indica que nenhum efeito aditivo ou substitutivo sobre o consumo voluntário de forragem foi observado (Tabela 3).

A substituição da ureia por albumina teve efeito linear sobre o consumo de $\mathrm{PB}(\mathrm{P}<0,10)$. Como a suplementação foi baseada no fornecimento de quantidade fixa de $\mathrm{PB}$, essa alteração pode ser atribuída ao consumo de $\mathrm{PB}$ oriunda da forragem. Embora o consumo de pasto não tenha sido alterado pela modificação na composição dos suplementos $(\mathrm{P}>0,10)$, as estimativas de consumo apresentaram pequena alteração entre suplementos $\mathrm{e}$ acompanharam as alterações observadas no consumo de PB (Tabela 3).

Nenhum efeito $(\mathrm{P}>0,10)$ foi observado sobre o tempo de trânsito intestinal ou sobre a taxa de passagem ruminal, cujos valores médios foram de 3,98 horas e $0,0240 \mathrm{~h}^{-1}$, respectivamente (Tabela 4). Consequentemente, pode-se afirmar que, apesar das diferenças numéricas, nenhum efeito foi observado sobre o tempo médio de retenção no rúmen retículo e no trato gastrintestinal total, cujas estimativas

Tabela 2 - Distribuição dos coeficientes empregados nos contrastes

\begin{tabular}{|c|c|c|c|c|c|}
\hline \multirow[t]{2}{*}{ Contraste $^{1}$} & \multicolumn{5}{|c|}{ Tratamentos } \\
\hline & MM (controle) & Ureia & $2 / 3$ ureia $+1 / 3$ albumina & $1 / 3$ ureia $+2 / 3$ albumina & Albumina \\
\hline $\mathrm{CO}$ & 4 & -1 & -1 & -1 & -1 \\
\hline Quadrático & 0 & -1 & 1 & 1 & -1 \\
\hline Cúbico & 0 & -1 & 3 & -3 & 1 \\
\hline
\end{tabular}

${ }^{1} \mathrm{CO}$ = controle versus suplementos; os efeitos linear, quadrático e cúbico são referentes à substituição da ureia por albumina no suplemento. 
médias para todos os tratamentos foram de 83,33 e 87,31 horas, respectivamente.

O fornecimento de suplementos ampliou, em média, a estimativa da taxa comum de latência e degradação $(\lambda)$ ( $\mathrm{P}<0,10)$, cujos valores médios observados foram de 0,0561 e $0,0569 \mathrm{~h}^{-1}$, para animais que não não receberam suplementos e aqueles sob suplementação, respectivamente (Tabela 5).
Embora não se tenha observado efeito significativo $(\mathrm{P}>0,10)$ da composição dos suplementos sobre $\lambda$, entre os suplementos, destacou-se o fornecimento de $2 / 3$ de PB oriunda da ureia, que elevou em $8,9 \%$ a estimativa de $\lambda$ em comparação ao tratamento controle, ao passo que, em média, os demais suplementos propiciaram valores similares ao observado na ausência de suplementação (Tabela 5).

Tabela 3 - Médias, coeficientes de variação (CV) e níveis descritivos de probabilidades para contrastes (valor-P) para os consumos de matéria seca (MS), MS de pasto (MSP), matéria orgânica (MO), MO de pasto (MOP), proteína bruta (PB), extrato etéreo (EE), fibra em detergente neutro corrigida para cinzas e proteína (FDNcp), carboidratos não-fibrosos (CNF), MS digerida (MSD), nutrientes digestíveis totais (NDT) e fibra em detergente neutro indigestível (FDNi) em função dos tratamentos

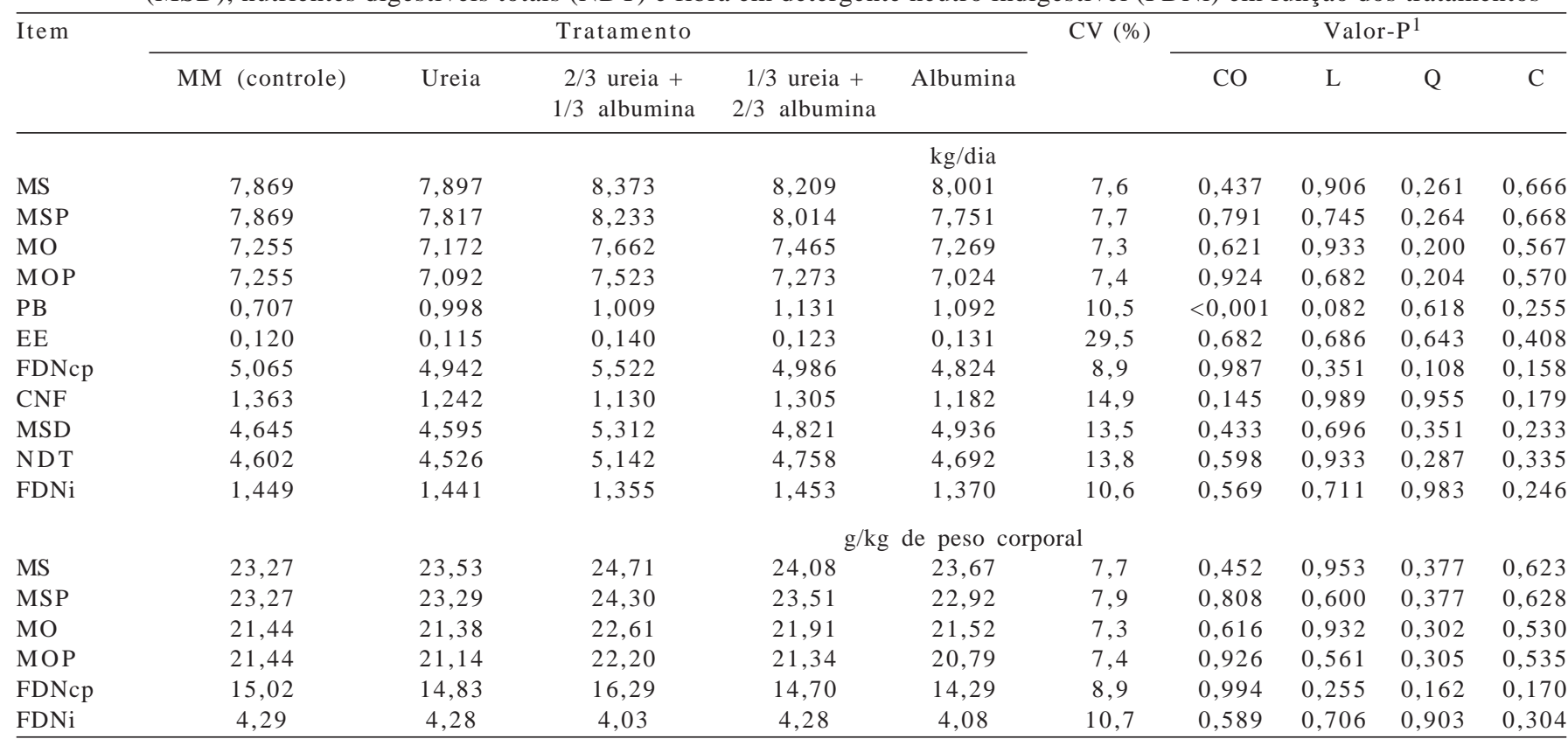

${ }^{1} \mathrm{CO}=$ controle versus suplementos; L, Q e C = efeitos linear, quadrático e cúbico da substituição da ureia por albumina.

Tabela 4 - Estimativas dos parâmetros da dinâmica de trânsito da fibra em detergente neutro em função dos tratamentos

\begin{tabular}{|c|c|c|c|c|}
\hline \multirow[b]{2}{*}{ Tratamentos ${ }^{2}$} & \multicolumn{3}{|c|}{ Parâmetro $^{1}$} & \multirow[b]{2}{*}{$\mathrm{DPA}^{3}$} \\
\hline & $\mathrm{Z}$ & $\tau$ & $\gamma$ & \\
\hline MM & 300,9 & 4,11 & 0,0249 & 81,0 \\
\hline $\mathrm{U}$ & 302,7 & 4,57 & 0,0228 & 80,7 \\
\hline $2 / 3 U$ & 263,4 & 4,19 & 0,0214 & 83,0 \\
\hline $1 / 3 U$ & 283,0 & 3,89 & 0,0247 & 82,5 \\
\hline A & 299,7 & 3,13 & 0,0261 & 82,2 \\
\hline Hipótese & & Valor-P & & \\
\hline Tratamentos 4 & - & 0,315 & 0,911 & - \\
\hline Suplementação ${ }^{5}$ & - & 0,225 & 0,812 & - \\
\hline Suplementos ${ }^{6}$ & - & 0,542 & 0,925 & - \\
\hline
\end{tabular}

${ }^{1} \mathrm{Z}$ = parâmetro sem interpretação biológica direta (ppm x h); $\tau=$ tempo de trânsito intestinal (h); $\gamma$ = parâmetro-taxa tempo-dependente relativo ao fluxo ruminal de partículas fibrosas $\left(\mathrm{h}^{-1}\right)$.

$2 \mathrm{MM}=$ controle; $\mathrm{U}=$ ureia; $2 / 3 \mathrm{U}=2 / 3$ ureia $+1 / 3$ albumina; $1 / 3 \mathrm{U}=1 / 3$ ureia $+2 / 3$ albumina; $A=$ albumina.

3 Desvio-padrão assintótico.

${ }^{4}$ Diferença entre todos os tratamentos avaliados.

${ }^{5}$ Diferença entre o controle e os tratamentos com suplementação.

${ }^{6}$ Diferença entre tratamentos com suplementação.
Tabela 5 - Estimativas dos parâmetros da dinâmica de degradação ruminal da fibra em detergente neutro em função dos tratamentos

\begin{tabular}{|c|c|c|c|c|}
\hline \multirow[b]{2}{*}{ Tratamentos ${ }^{2}$} & \multicolumn{3}{|c|}{ Parâmetro $^{1}$} & \multirow[b]{2}{*}{$\mathrm{DPA}^{3}$} \\
\hline & Bp & Ip & $\lambda$ & \\
\hline MM & 61,24 & 38,76 & 0,0561 & 63,8 \\
\hline $\mathrm{U}$ & 63,40 & 36,60 & 0,0518 & 64,1 \\
\hline $2 / 3 U$ & 58,46 & 41,54 & 0,0611 & 63,3 \\
\hline $1 / 3 U$ & 60,65 & 39,35 & 0,0574 & 62,1 \\
\hline A & 57,02 & 42,98 & 0,0572 & 62,3 \\
\hline Hipótese & & Valor-P & & \\
\hline Tratamentos 4 & - & - & $<0,001$ & - \\
\hline Suplementação ${ }^{5}$ & - & - & 0,039 & - \\
\hline Suplementos 6 & - & - & 0,182 & - \\
\hline
\end{tabular}

${ }^{1} \mathrm{Bp}$ = fração padronizada potencialmente degradável (\%); Ip = fração padronizada indegradável (\%); $\lambda=$ taxa comum de latência e degradação da fração potencialmente degradável $\left(\mathrm{h}^{-1}\right)$.

$2 \mathrm{MM}=$ controle; $\mathrm{U}=$ ureia; $2 / 3 \mathrm{U}=2 / 3$ ureia $+1 / 3$ albumina; $1 / 3 \mathrm{U}=1 / 3$ ureia $+2 / 3$ albumina; $A=$ albumina.

3 Desvio-padrão assintótico.

${ }^{4}$ Diferença entre todos os tratamentos avaliados.

5 Diferença entre o controle e os tratamentos com suplementação.

${ }^{6}$ Diferença entre tratamentos com suplementação. 
Em função da similaridade entre tratamentos $(\mathrm{P}>0,10)$ quanto à passagem ruminal e pressupondo-se que a dimensão das estimativas das frações potencialmente degradável e indegradável sejam características intrínsecas ao substrato, os parâmetros secundários da dinâmica ruminal da FDN foram estimados utilizando-se os valores médios obtidos para os parâmetros Bp (60,15\%), Ip (39,85\%) e $\gamma\left(0,0240 \mathrm{~h}^{-1}\right)$. Salienta-se que, sob estes pressupostos, o efeito de repleção ruminal da fração indegradável da FDN assumiu valor único entre tratamentos (33,18 horas).

Neste contexto, refletindo o comportamento observado para as estimativas da taxa de degradação, a utilização de suplemento composto por 2/3 de PB oriunda da ureia reduziu em $6,5 \%$ o efeito de repleção ruminal da FDN potencialmente degradável e elevou em 2,8\% a fração efetivamente degradada da FDN em relação ao controle, sem suplementação (Tabela 6). Os demais suplementos causaram poucas alterações sobre os parâmetros secundários da dinâmica ruminal da FDN, com exceção do suplemento baseado exclusivamente em ureia, o qual elevou em 8,4 e 6,3\% a latência discreta e o efeito de repleção ruminal da FDN potencialmente degradável, respectivamente (Tabela 6).

\section{Discussão}

O consumo voluntário de forragem pelo animal depende da quantidade e qualidade da forragem ofertada, ou seja, quanto maior a possibilidade do animal selecionar materiais com maiores proporções de FDNpd, menores os entraves sobre no consumo.

Níveis máximos de consumo e desempenho animal estão relacionados à oferta de forragem de cerca de duas a três vezes a necessidade diária do animal, ou seja, de 10 a 12\% do PC seriam necessários para que o animal em pastejo apresente máximo desempenho (Hodgson, 1990). Contudo, como nem toda MS consumida pelo animal é realmente aproveitada, deve-se basear na disponibilidade de MSpd do pasto, cuja recomendação seria de 4 a $5 \%$ do peso corporal dos animais para haver desempenho satisfatório dos animais criados a pasto (Paulino et al., 2002).
Segundo Paulino et al. (2008), a MSpd constitui medida integradora dos aspectos quali e quantitativos do pasto, o que permite maior precisão na avaliação da real capacidade de suporte e desempenho animal na área utilizada. Considerando a disponibilidade média de MSpd nos períodos experimentais (10,7 t/ha ou 3,64 t/piquete) e o peso médio dos animais durante o experimento (340,1 kg), observou-se que a disponibilidade instantânea de MSpd nos pastos foi de 10,6 vezes o peso dos animais, o que possivelmente pode ser considerada como não-restritiva em relação à possibilidade de maximização do consumo de forragem.

Por outro lado, considerando-se apenas os aspetos químicos da forragem (Tabela 1), o teor de PB médio situou-se acima dos patamares mínimos (7-8\% PB) necessários para que os microrganismos ruminais apresentem plena capacidade de degradação dos substratos fibrosos da forragem basal (Lazzarini et al., 2009; Sampaio et al., 2009). Em termos de pastos tropicais durante o período das águas, pode-se considerar a forragem avaliada neste experimento como de média a alta qualidade.

A similaridade do consumo de MS de pasto entre animais sob suplementação e aqueles do grupo controle (Tabela 3) indica que o fornecimento de suplementos proteicos não teve nenhum efeito substitutivo ou aditivo sobre o consumo de pasto. Este comportamento torna a suplementação estritamente proteica diferenciada em relação àquela com suplementos proteico-energéticos, na qual efeitos substitutivos em relação ao consumo de forragem são comumente observados (Detmann et al., 2001b; Costa et al., 2011).

Por outro lado, segundo os conceitos teóricos aplicados à nutrição de bovinos em pastejo de forragem de alta qualidade, haveria nestas condições desbalanço metabólico gerado pelas características da dieta ingerida (Paulino et al., 2008). Pastos tropicais durante o período das águas tenderiam a apresentar alta degradabilidade da PB (Poppi \& McLennan, 1995; Detmann et al., 2005b). Isso poderia ser compatível com a presente situação, uma vez que somente $25 \%$ da PB da dieta basal encontrava-se na forma associada aos compostos fibrosos insolúveis (Tabela 1).

Tabela 6 - Estimativas dos parâmetros secundários da dinâmica ruminal da fibra em detergente neutro em função dos tratamentos

\begin{tabular}{lccccc}
\hline & \multicolumn{4}{c}{ Tratamento $^{1}$} \\
\cline { 2 - 5 } Parâmetro $^{2}$ & MM (controle) & Ureia & $2 / 3$ ureia $+1 / 3$ albumina & $1 / 3$ ureia $+2 / 3$ albumina & Albumina \\
\hline FEDT & 47,17 & $45,86(97,2)$ & $48,48(102,8)$ & $47,53(100,8)$ & $47,48(100,7)$ \\
FED & 78,42 & $76,24(97,2)$ & $80,60(102,8)$ & $79,02(100,8)$ & $78,94(100,7)$ \\
LAG & 5,02 & $5,44(108,4)$ & $4,61(91,8)$ & $4,91(97,8)$ & $4,93(98,2)$ \\
RRpd & 17,87 & $19,00(106,3)$ & $16,70(93,5)$ & $17,55(98,2)$ & $17,60(98,5)$ \\
\hline
\end{tabular}

${ }^{1}$ Os valores entre parênteses correspondem ao percentual em relação ao tratamento controle.

2 FEDT = fração efetivamente degradada em relação à FDN total (\%); FED = fração efetivamente degradada em função da FDN potencialmente degradável (\%); LAG = latência discreta (h); RRpd = efeito de repleção ruminal da FDN potencialmente degradável (h). 
Nestas circunstâncias, devido à menor velocidade de degradação das fontes energéticas da forragem, representadas principalmente pela fibra insolúvel, haveria baixa assimilação microbiana dos compostos nitrogenados no rúmen, os quais seriam eliminados na urina. Assim, como seria reduzida a disponibilidade de proteína metabolizável em relação à energia oriunda da forragem (Detmann et al., 2005b), o excesso relativo de compostos cetogênicos no metabolismo animal seria eliminado por ciclos fúteis, ampliando a geração de calor corporal e inibindo o consumo voluntário (Poppi \& McLennam, 1995).

Neste contexto, em termos teóricos, os suplementos deveriam ser formulados para ampliar o fornecimento de proteína metabolizável, o que poderia ser obtido via suprimento de energia de rápida disponibilidade no rúmen para a ampliação da assimilação dos compostos nitrogenados da forragem (Paulino et al., 2008).

Assim, o fornecimento de fontes proteicas prontamente degradáveis não propiciariam melhorias na relação proteína metabolizável:energia metabolizável, podendo, inclusive, acarretar redução no consumo voluntário devido à elevação no metabolismo hepático e na amônia sanguínea e intracelular, que implicariam sensações de mal-estar nos animais (Detmann et al., 2007).

Contudo, de forma similar ao obtido neste trabalho, a manutenção do consumo de pasto com o fornecimento de suplementos com níveis elevados de PB foram também observados por outros autores em bovinos durante o período das águas (Zervoudakis, 2003; Zervoudakis et al., 2008; Porto, 2009), o que denota que os fundamentos teóricos apresentados anteriormente podem não representar completamente a relação entre a suplementação com fontes proteicas degradáveis e a resposta animal.

Os resultados deste trabalho agregam aos obtidos por Ventura et al. (1975), que, forneceram suplemento a ovinos alimentados com capim-pangola (Digitaria decumbens) com farelo de soja (aproximadamente $0,1 \%$ do PC em PB) e não verificaram alteração do consumo de forragem quando esta apresentava 13,7\% de PB. Contudo, influências negativas da suplementação foram verificadas por esses autores quando a forragem basal apresentava $17,8 \%$ de PB. Isto sugere que a suplementação com compostos nitrogenados somente pode acarretar efeitos deletérios sobre o consumo em níveis de PB basal acima daqueles normalmente observados em forragens tropicais durante $\mathrm{o}$ período das águas, o que parece justificar a não-observação dos efeitos teóricos descritos anteriormente.

Sob condições de entraves físicos ao consumo, o estímulo sobre a taxa de degradação da FDN ampliaria a velocidade de retirada dos compostos fibrosos insolúveis do ambiente ruminal, os quais estão associados à repleção física (Allen, 1996; Paulino et al., 2008). Com isto, ampliar-se-ia o turnover ruminal, o que implicaria aumento no consumo de forragem (Detmann et al., 2009). Contudo, a ausência de efeitos sobre o consumo de FDNi (a qual somente é retirada do ambiente ruminal por passagem) (Tabela 3) e sobre as estimativas diretas do fluxo ruminal dos compostos fibrosos (Tabela 4) indica que o turnover ruminal não foi alterado pela suplementação, mesmo com estímulos sobre a degradação da FDN (Tabela 6).

Sob condições de pastejo, notadamente em regiões tropicais, os entraves físicos são normalmente definidos como o mecanismo predominante que determina o limite do consumo voluntário de forragem. Isto parece ser aplicado com propriedade para animais alimentados com forragem de baixa qualidade (Lazzarini et al., 2009; Sampaio et al.; 2009). Contudo, mesmo nestas condições, mecanismos fisiológicos ou metabólicos de controle parecem atuar sobre o consumo (Detmann et al., 2009). As estimativas médias de consumo de FDN se situaram em patamares superiores ao que seria esperado quando mecanismos físicos de controle de consumo são predominantes (Mertens, 1994). Associando-se isto à não-alteração do consumo de FDN, mesmo com estímulos que teoricamente reduziriam o efeito físico de repleção (Tabelas 8 e 9), pode-se inferir que aspectos metabólicos de regulação do consumo sejam mais proeminentes quando pasto de alta qualidade é disponibilizado aos animais, como destacado por outros autores (Detmann et al.; 2005b; Detmann et al., 2010; Costa et al., 2011).

\section{Conclusões}

A suplementação de bovinos com fontes de compostos nitrogenados degradáveis no rúmen proteicos ou nãoproteicos durante o período das águas não afeta o consumo voluntário de pasto.

\section{Referências}

ALLEN, M.S. Physical constraints on voluntary intake of forages by ruminants. Journal of Animal Science, v.74, p.3063-3075, 1996.

CASALI, A.O.; DETMANN, E.; VALADARES FILHO, S.C. et al. Influência do tempo de incubação e do tamanho de partículas sobre os teores de compostos indigestíveis em alimentos e fezes bovinas obtidos por procedimentos in situ. Revista Brasileira de Zootecnia, v.37, p.335-342, 2008.

CARVALHO, I.P.C.; DETMANN, E.; MANTOVANI, H.C. et al. In vitro growth and antimicrobial activity of lactic acid bacteria from rumen fluid according to energy or nitrogen source. Revista Brasileira de Zootecnia, v.40, p.1260-1265, 2011. 
CONE, J.W.; Van GELDER, A.H. Influence of protein fermentation on gas production profiles. Animal Feed Science and Technology, v.76, p.251-264, 1999.

COSTA, V.A.C.; DETMANN, E.; VALADARES FILHO, S.C. et al. Degradação in vitro da fibra em detergente neutro de forragem tropical de alta qualidade em função da suplementação com proteína e/ou carboidratos. Revista Brasileira de Zootecnia, v.38, p.1803-1811, 2009.

COSTA, V.A.C.; DETMANN, E.; PAULINO, M.F. et al. Consumo e digestibilidade em bovinos em pastejo durante o período das águas suplementados com diferentes fontes de compostos nitrogenados e de carboidratos. Revista Brasileira de Zootecnia, v.40, 1788-1798, 2011.

DETMANN, E.; PAULINO, M.F.; ZERVOUDAKIS, J.T. et al. Cromo e indicadores internos na determinação do consumo de novilhos mestiços, suplementados, a pasto. Revista Brasileira de Zootecnia, v.30, p.1600-1609, 2001a.

DETMANN, E.; PAULINO, M.F.; ZERVOUDAKIS, J.T. et al. Suplementação de novilhos mestiços durante a época das águas: parâmetros ingestivos e digestivos. Revista Brasileira de Zootecnia, v.30, p.1340-1349, 2001b.

DETMANN, E.; PAULINO, M.F.; CECON, P.R. et al. Níveis de proteína em suplementos para terminação de bovinos em pastejo durante o período de transição seca/águas: consumo voluntário e trânsito de partículas. Revista Brasileira de Zootecnia, v.34, p.1371-1379, 2005a.

DETMANN, E.; PAULINO, M. F.; VALADARES FILHO, S.C. et al. Níveis de proteína em suplementos para terminação de bovinos em pastejo durante período de transição seca/águas: digestibilidade aparente e parâmetros do metabolismo ruminal e compostos. Revista Brasileira de Zootecnia, v.34, p.1380-1391, 2005b.

DETMANN, E.; PAULINO, M.F; VALADARES FILHO, S.C. et al. Fatores controladores de consumo em suplementos múltiplos fornecidos ad limitum para bovinos manejados a pasto. Cadernos Técnicos de Veterinária e Zootecnia, v.55, p.73-93, 2007.

DETMANN, E.; PAULINO, M.F.; VALADARES FILHO, S.C. Avaliação nutricional de alimentos ou de dietas? Uma abordagem conceitual. In: SIMPÓSIO DE PRODUÇÃO DE GADO DE CORTE, 6., 2008, Viçosa, MG. Anais... Viçosa, MG: DZOUFV, 2008. p.21-52.

DETMANN, E.; PAULinO, M.F.; MANTOVANI, H.C. et al. Parameterization of ruminal fibre degradation in low-quality tropical forage using Michaelis-Menten kinetics. Livestock Science, v.126, p.136-146, 2009.

DETMANN, E.; PAULINO, M.F.; VALADARES FILHO, S.C. Otimização do uso de recursos forrageiros basais. In: SIMPÓSIO DE PRODUÇÃO DE GADO DE CORTE, 7., 2010, Viçosa, MG. Anais... Viçosa, MG: DZO-UFV, 2010. p.191-240.

DETMANN, E.; VALADARES FILHO, S.C. On the estimation of non-fibrous carbohydrates in feeds and diets. Arquivo Brasileiro de Medicina Veterinária e Zootecnia, v.62, p.980-984, 2010.

ELLIS, W.C.; MATIS, J.H.; HILL, T.M. et al. Methodology for estimating digestion and passage kinetics of forages. In: FAHEY JUNIOR, G.C. (Ed.) Forage quality, evaluation and utilization. Madison: American Society of Agronomy, 1994. p.682-756.

FIGUEIREDO, D.M.; PAULINO, M.F.; DETMANN, E. et al. Fontes de proteína em suplementos múltiplos para bovinos em pastejo no período das águas. Revista Brasileira de Zootecnia, v.37, p.2222-2232, 2008.

HODGSON, J. Grazing management: science into practice. Longman: Handbooks in Agriculture, 1990. 203p.

LAZZARINI, I.; DETMANN, E.; SAMPAIO, C.B. et al. Dinâmicas de trânsito e degradação da fibra em detergente neutro em bovinos alimentados com forragem tropical de baixa qualidade e compostos nitrogenados. Arquivo Brasileiro de Medicina Veterinária e Zootecnia, v.61, p.635-647, 2009.
LICITRA, G.; HERNANDES, T.M.; Van SOEST, P.J. Standardization of procedures for nitrogen fractionation of ruminant feeds. Animal Feed Science and Technology, v.57, p.347-358, 1996. McCALLAN, A.B.; SMITH, R.H. Factors influencing the digestion of dietary carbohydrates between mouth and abomasum. British Journal of Nutrition, v.50, p.444-454, 1983.

MERTENS, D.R. Regulation of forage intake. In: FAHEY JUNIOR, G.C. (Ed.) Forage quality, evaluation and utilization. Madison: American Society of Agronomy, 1994. p.450-493.

MERTENS, D.R. Gravimetric determination of amylase-treated neutral detergent fiber in feeds with refluxing in beakers or crucibles: collaborative study. Journal of AOAC International, v.85, p.1217-1240, 2002.

OLIVEIRA, A.L.F.; CABRAL, L.S.; VALADARES FILHO, S.C. et al. Efeito da fermentação de proteínas na cinética de produção de gases in vitro. In: ZOOTEC’2005, Campo Grande. Anais... Campo Grande: Associação Brasileira de Zootecnistas, 2005. (CD-ROM).

ØRSKOV, E.R.; McDONALD, I. The estimation of protein degradability in the rumen from incubation measurements of feed weighted according to rate of passage. Journal of Agricultural Science, v.92, p.499-503, 1979.

PAEZ-BERNAL, D.M. Dinâmica de degradação in vitro da fibra em detergente neutro de capim-braquiária em função de suplementação com diferentes fontes de compostos nitrogenados e carboidratos. 2007. 49f. Dissertação (Mestrado em Zootecnia) - Universidade Federal de Viçosa, Viçosa, MG.

PAULINO, M.F.; ZERVOUDAKIS, J.T.; MORAES, E.H.B.K. et al. Bovinocultura de ciclo curto em pastagens. In: SIMPÓSIO DE PRODUÇÃO DE GADO DE CORTE, 3., 2002 Viçosa, MG. Anais... Viçosa, MG: DZO-UFV, 2002. p.153-196.

PAULINO, M.F.; DETMANN, E.; VALENTE, E.E.L. et al. Nutrição de bovinos em pastejo. In: SIMPÓSIO SOBRE MANEJO ESTRATÉGICO DA PASTAGEM, 4., 2008, Viçosa, MG. Anais... Viçosa, MG: DZO-UFV, 2008. p.131-169.

POPPI, D.P.; McLENNAN, S.R. Protein and energy utilization by ruminants at pasture. Journal of Animal Science, v.73, p.278-290, 1995 .

PORTO, M.O. Suplementos múltiplos para bovinos de corte nas fases de cria, recria e terminação em pastagens de Brachiaria decumbens. 2009. 140f. Tese (Doutorado em Zootecnia) - Universidade Federal de Viçosa, Viçosa, MG.

PORTO, M.O.; PAULINO, M.F.; VALADARES FILHO, S.C. et al. Fontes suplementares de proteína para novilhos mestiços em recria em pastagens de capim-braquiária no período das águas: desempenho produtivo e econômico. Revista Brasileira de Zootecnia, v.38, p.1553-1560, 2009.

REGAZZI, A.J. Teste para verificar a igualdade de parâmetros e identidade de modelos de regressão não-linear. Ceres, v.50, p.9-26, 2003.

SAMPAIO, C.B.; DETMANN, E.; LAZZARINI, I. et al. Rumen dynamics of neutral detergent fiber in cattle fed low-quality tropical forage and supplemented with nitrogenous compounds. Revista Brasileira de Zootecnia, v.38, p.560-569, 2009.

SILVA, D.J.; QUEIROZ, A.C. 2002. Análise de alimentos: métodos químicos e biológicos. 3.ed. Viçosa, MG: Editora UFV, 2002. $235 p$.

TITGEMEYER, E.C.; ARMENDARIZ, C.K.; BINDEL, D.J. et al. Evaluation of titanium dioxide as a digestibility marker for cattle. Journal of Animal Science, v.79, p.1059-1063, 2001.

UDÉN, P.; COLUCCI, P.E.; Van SOEST, P.J. Investigation of chromium, cerium and cobalt as markers in digesta. Rate of passage studies. Journal of Science Food and Agriculture, v.31, p.625-632, 1980.

VALADARES FILHO, S.C.; PAULINO, P.V.R.; VALADARES, R.F.D. et al. Exigências nutricionais de zebuínos no Brasil. II. Proteína. In: VALADARES FILHO, S.C.; PAULINO, P.V.R.; MAGALHÃES, K.A. (Eds.) Exigências nutricionais de 
zebuínos e tabelas de composição de alimentos BR-Corte. Viçosa, MG: DZO-UFV, 2006. p.75-84.

Van MILGEN, J.; MURPHY, L.L.; BERGER, L.L. A compartmental model to analyze ruminal digestion. Journal of Dairy Science, v.74, p.2515-2529, 1991.

VENTURA, M.; MOORE, J.E.; RUELKE, O.C. et al. Effect of maturity and protein supplementation on voluntary intake and nutrient digestibility of pangola digitaria grass hays. Journal of animal Science, v.40, p.769-774, 1975.

VIEIRA, R.A.M.; PEREIRA, J.C.; MALAFAIA, P.A.M. et al. Application of non-linear models in the description of in situ degradation profiles of the elephant grass (Pennisetum purpurem Schum. Mineiro variety). Animal Feed Science and Technology, v.66, p.197-210, 1997.

WALDO, D.R.; SMITH, L.W.; COX, E.L. Model of cellulose disappearance from the rumen. Journal of Dairy Science, v.55, p.125-129, 1972.
WILLIANS, C.H.; DAVID, D.J.; IISMA, O. The determination of chromic oxide in faeces samples by atomic absorption spectrophotometry. Journal of Agricultural Science, v.59, p.381-385, 1962.

ZERVOUDAKIS, J.T. Suplementos multiplos de auto controle de consumo e freqüência de suplementação, na recria de novilhos durante os períodos das águas e transição águassecas. 2003. 78f. Tese (Doutorado em Zootecnia) - Universidade Federal de Viçosa, Viçosa, MG.

ZERVOUDAKIS, J.T.; PAULINO, M.F.; CABRAL, L.S. et al. Suplementos múltiplos de auto controle de consumo na recria de novilhos no período das águas. Ciência e Agrotecnologia, v.32, p.1968-1973, 2008.

ZORZI, K.; DETMANN, E.; QUEIROZ, A.C. et al. In vitro degradation of neutral detergent fiber of high-quality tropical forage according to supplementation with different nitrogenous compounds. Revista Brasileira de Zootecnia, v.38, p.964-971, 2009. 